\title{
Chiari type I malformation: role of the Chiari Severity Index and Chicago Chiari Outcome Scale
}

\author{
Ranbir Ahluwalia, BS, 1,2 Jarrett Foster, BS, 1,3 Earllondra Brooks, MD, 1,4 Jaims Lim, MD, 1,5 \\ Shilin Zhao, PhD, ${ }^{1}$ Stephen R. Gannon, CCRP, ${ }^{1}$ Bradley Guidry, BS, ${ }^{6}$ John Wellons III, MSPH, MD,, 7 \\ and Chevis N. Shannon, DrPH, MBA, MPH'1,7
}

\begin{abstract}
${ }^{1}$ Surgical Outcome Center for Kids, Monroe Carell Jr. Children's Hospital at Vanderbilt, Nashville, Tennessee; ${ }^{2}$ Florida State University College of Medicine, Tallahassee, Florida; ${ }^{3}$ University of South Carolina School of Medicine, Columbia, South Carolina; ${ }^{4}$ Department of Neurology, Harvard Brigham and Women's Hospital/Massachusetts General Hospital, Boston, Massachusetts; ${ }^{5}$ Department of Neurological Surgery, University at Buffalo, New York; ${ }^{6}$ Vanderbilt University School of Medicine, Nashville, Tennessee; and 'Department of Neurological Surgery, Vanderbilt University Medical Center, Nashville, Tennessee
\end{abstract}

\begin{abstract}
OBJECTIVE The authors aimed to determine whether the Chiari Severity Index (CSI), and other clinical variables, can be used as a predictor of postoperative outcomes for Chiari type I malformation (CM-I) using the modified Chicago Chiari Outcome Scale (mCCOS) as the postoperative measure.

METHODS The cohort included patients 18 years of age and younger who were treated for CM-I between 2010 and 2015 who had at least 12 months of clinical and radiographic follow-up. CSI grades were assigned using preoperative clinical and neuroimaging data. Clinical, radiographic, and operative data were obtained from medical records. KruskalWallis tests and Spearman correlations were conducted to assess for differences among CSI grades. Linear and ordinal regressions were conducted to evaluate predictors of the mCCOS and its components. Statistical significance was set a priori at $p<0.05$.
\end{abstract}

RESULTS A total of 65 patients were included in the final cohort. The average age at the time of surgery and the mean mCCOS score were $9.8 \pm 4.9$ years and $10.4 \pm 1.4$, respectively. There were no significant differences in the mean mCCOS scores or CSI grades. Pre- and postoperative syrinx sizes were similar across the total patient cohort with median sizes of 7.4 and $3.7 \mathrm{~mm}$, respectively. After controlling for age at the time of surgery, whether duraplasty and/ or arachnoid dissection was performed, CSI preoperative score did not predict postoperative mCCOS score. No clinical variable could predict total mCCOS score. When the mCCOS was broken down into 3 subcomponents (pain, non-pain, and complications), only one relationship was identified. Those patients who presented with no headache had a statistically significant decrease in their pain (neck pain, shoulder pain, or dysesthesia in the upper extremities) as measured by the pain component of the $\operatorname{mCCOS}\left(\chi^{2}[2, n=20]=6.43, p=0.04\right)$. All other preclinical predictors, including CSI grades, were nonsignificant in demonstrating correlations to the mCCOS subcomponents.

CONCLUSIONS CSI grade was not found to be a marker of surgical outcome as measured by the mCCOS in this study. There were no correlations between the clinical variables and covariates investigated with the mCCOS. The lack of variation in mCCOS scores across this cohort may suggest that the mCCOS is not adequate for detecting differences in postsurgical outcomes. Further investigation is warranted to make this determination.

https://thejns.org/doi/abs/10.3171/2020.2.PEDS19770

KEYWORDS Chiari Severity Index; Chicago Chiari Outcome Scale; posterior fossa decompression; outcomes

$\mathrm{C}$ HIARI type I malformation (CM-I) is the most common form of CM and is due to the downward displacement of the cerebellar tonsils through the foramen magnum., ${ }^{1,23}$ Clinical presentations vary widely, but many patients have symptoms of obstructive hydrocephalus such as vision changes, nausea, and weakness, and most commonly headache and neck pain., ${ }^{2,3}$
Although most studies show favorable surgical outcomes for CM-I in symptomatic patients, there are no established or clear indications for surgery aside from progressively worsening symptoms or presence of a syrinx. ${ }^{4,5}$ While posterior craniocervical decompression is the most common surgical procedure to treat CM-I, there is a lack of consensus on surgical guidelines and indications, with

ABBREVIATIONS CCOS = Chicago Chiari Outcome Scale; CM-I = Chiari type I malformation; $C S I=$ Chiari Severity Index; $\mathrm{mCCOS}=$ modified Chicago Chiari Outcome Scale.

SUBMITTED December 22, 2019. ACCEPTED February 25, 2020.

INCLUDE WHEN CITING Published online May 22, 2020; DOI: 10.3171/2020.2.PEDS19770. 


\begin{tabular}{|c|c|c|c|}
\hline \multirow[b]{2}{*}{ Neuroimaging Grade } & \multicolumn{3}{|c|}{ Clinical Grade } \\
\hline & $\begin{array}{c}1 \text { (poorly localized or classic } \\
\text { CM headache) }\end{array}$ & $\begin{array}{c}2 \text { (frontotemporal or no } \\
\text { headache) }\end{array}$ & 3 (myelopathic symptoms) \\
\hline A (syrinx < 6 mm or no syrinx) & \multirow{2}{*}{ CSI grade $1(n=24)$} & \multicolumn{2}{|c|}{ CSI grade $2(n=12)$} \\
\hline$B($ syrinx $\geq 6 \mathrm{~mm}$ ) & & \multicolumn{2}{|c|}{ CSI grade $3(n=17)$} \\
\hline
\end{tabular}

Based on information provided by Greenberg JK, Yarbrough CK, Radmanesh A, et al. The Chiari Severity Index: a preoperative grading system for Chiari malformation type 1. Neurosurgery. 2015;76:279-285.

many case series reporting different optimal surgical techniques. ${ }^{6-11}$ The Chicago Chiari Outcome Scale (CCOS) was published by Aliaga et al. in 2012, which provided the first tool to compare postoperative outcomes across surgical treatments for CM-I. ${ }^{12}$ Furthermore, the Chiari Severity Index (CSI) was published by Greenberg et al. in 2015 as a preoperative tool to grade the severity of CM-I. ${ }^{13}$

CSI grade is determined by a combination of a neuroimaging grade and a clinical grade, and is physician-reported. The neuroimaging grade is based on the presence and/or size of a syrinx. Clinical grade is determined by the presence and type of headache as well as the presence of myelopathic symptoms. Table 1 demonstrates the grading scale based on these components. The CCOS has 4 main components (pain, non-pain, functionality, and complications), which are scored from 1 to 4 for a total final score ranging from 4 to 16 . The modified CCOS (mCCOS) includes all components except for functionality, resulting in a final score range from 3 to 12 . Table 2 demonstrates how these scores are evaluated.

We aimed to determine whether the CSI can be used as a predictor for postoperative outcomes for CM-I using the mCCOS as the postoperative measure. We explored the relationship between the CSI and clinical variables indicative of surgical outcome, as measured by the mCCOS, in hopes to better understand the role of surgical intervention in the symptomatic management of CM-I.

\section{Methods}

\section{Inclusion and Exclusion Criteria}

All patients at the Monroe Carell Jr. Children's Hospital with a diagnosis of CM-I who underwent a primary posterior fossa decompression at $\leq 18$ years of age between Jan- uary 1, 2010, and December 1, 2015, were identified and included. Patients were excluded if they had 1) incomplete follow-up, 2) a surgical outcome that could not be used to calculate an mCCOS score, or 3) a preoperative evaluation that resulted in an inability to calculate a CSI score. A total of 204 medical records were reviewed, of which 65 met the inclusion criteria (Fig. 1).

\section{Clinical Data and Follow-Up}

Clinical, radiographic, and surgical data were collected. Preoperative images were reviewed to look for the presence of a syrinx and the size was categorized as $\geq 6 \mathrm{~mm}$ or $<6 \mathrm{~mm}$. Syrinx diameter measurements were taken on T2-weighted MRI sequences unless it was unavailable, in which case T1-weighted MRI sequences were used.

Follow-up data were collected from the day of initial surgical intervention until one of the following criteria was met: 1) an additional intracranial or spinal procedure, unrelated to the CM-I correction, was conducted within a 6-month postoperative period; 2) 18 months postoperatively without additional unrelated surgeries; 3 ) the patient was released from follow-up by their primary neurosurgeon; or 4) the patient died. Follow-up data were obtained until 12 months postoperatively unless patients were released earlier from follow-up. Additional data extending up to 6 months were recorded if patients had adequate clinical data in order to document any changes in syrinx size on their second postoperative MRI, which was usually repeated at 12-18 months after surgery.

Loss to follow-up was defined as missing a 12-month postoperative clinic visit (unless the patient had been released from follow-up), or contact via phone call with the parents (or with those patients $\geq 18$ years of age) was unable to be made after 3 attempts. Patients whose available

TABLE 2. The CCOS

\begin{tabular}{lcccc}
\hline \multicolumn{1}{c}{ Pain } & Non-pain & Functionality & Complications & Total Score \\
\hline 1 - Worse & 1 - Worse & 1 - Unable to attend & $\begin{array}{c}1 \text { - Persistent complication, } \\
\text { poorly controlled }\end{array}$ & $\begin{array}{c}3 \text { - Incapacitated } \\
\text { outcome }\end{array}$ \\
\hline $\begin{array}{c}\text { 2 - Unchanged and refractory to } \\
\text { medication }\end{array}$ & $\begin{array}{c}2 \text { - Unchanged or improved } \\
\text { but impaired }\end{array}$ & $\begin{array}{c}2 \text { - Moderate impairment } \\
(<50 \% \text { attendance })\end{array}$ & $\begin{array}{c}2 \text { - Persistent complication, well } \\
\text { controlled }\end{array}$ & 6 - Impaired outcome \\
$\begin{array}{c}3 \text { - Improved or controlled with } \\
\text { medication }\end{array}$ & $\begin{array}{c}3 \text { - Improved and unim- } \\
\text { paired }\end{array}$ & $\begin{array}{c}3 \text { - Mild impairment }(>50 \% \\
\text { attendance })\end{array}$ & 3 - Transient complication & 9 - Functional outcome \\
\hline - Resolved & 4 - Resolved & 4 - Fully functional & 4 - Uncomplicated course & 12 - Excellent outcome \\
\hline
\end{tabular}

The mCCOS does not include a functionality component. Table from Aliaga L, Hekman KE, Yassari R, et al. A novel scoring system for assessing Chiari malformation type I treatment outcomes. Neurosurgery. 2012;70(3):656-665, by permission of the Congress of Neurological Surgeons. 


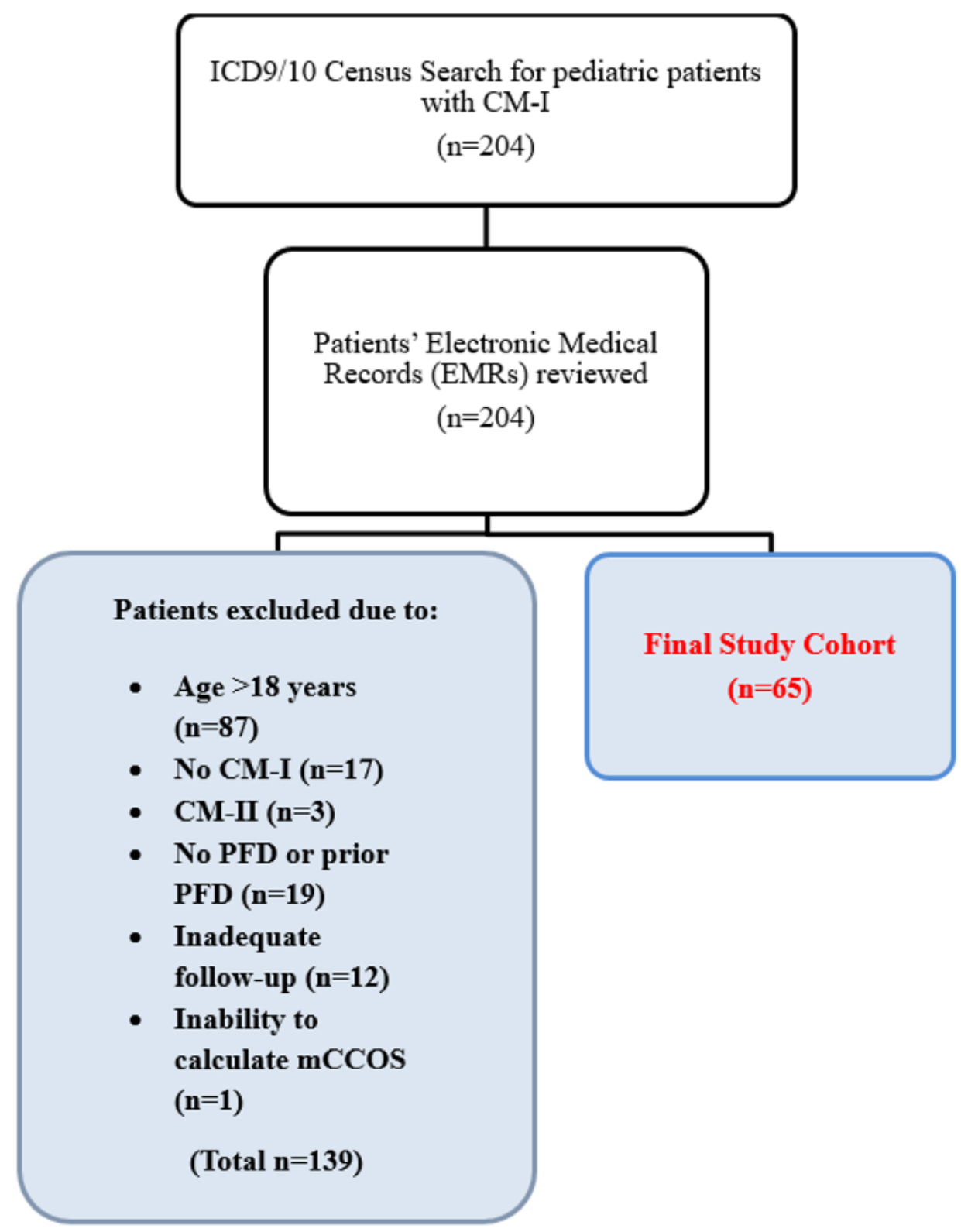

FIG. 1. Inclusion and exclusion flowchart. CM-II = CM type II; PFD = posterior fossa decompression. Figure is available in color online only.

information did not fully describe their outcome and/or patients with inadequate follow-up were contacted by a single author of the study (E.B.) to complete their clinical data.

\section{Predictors}

The CSI, a preoperative grading system, was applied to all symptomatic patients in this study as described by Greenberg et al. (described in Table 1 ). ${ }^{13}$ A preoperative CSI score and postoperative CCOS score were calculated for each patient. In addition, preoperative clinical variables of interest were collected including headache location (posterior, other, or none), presence of preoperative symptoms (myelopathic symptoms, other symptoms, or none), presence of peripheral neuropathy (yes or no), and syrinx size ( $\geq 6 \mathrm{~mm}$ or $<6 \mathrm{~mm}$ ). Myelopathic symptoms were defined as numbness, weakness, hyperreflexia, or unsteady gait. ${ }^{13}$ Peripheral neuropathy was defined as presence of paresthesias. ${ }^{14}$ Surgical characteristics, i.e., whether or not a duraplasty and/or arachnoid dissection was performed, were recorded.

\section{Outcome Measure}

Outcomes were assessed by one reviewer (E.B.) using the mCCOS at the end of follow-up. The original CCOS is a 16-point tool that uses four general categories-pain symptoms, non-pain symptoms, functionality, and complications - as a measure of postoperative outcome. A lower score is correlated with a worse surgical outcome. ${ }^{12,15} \mathrm{In}$ stead of the standard CCOS, we utilized a modified CCOS, 
TABLE 3. Patient demographics

\begin{tabular}{lc}
\hline \multicolumn{1}{c}{ Characteristic } & Value $(\%)$ \\
\hline Mean age at time of surgery \pm SD, yrs & $9.8 \pm 4.9$ \\
\hline Females & $39(60)$ \\
\hline Race & $56(86.2)$ \\
\hline Caucasian & $8(12.3)$ \\
\hline African American & $1(1.5)$ \\
\hline Asian/Pacific Islander & $10.4 \pm 1.4$ \\
\hline Mean mCCOS \pm SD
\end{tabular}

which excluded the functionality subscore given the ambiguity in defining functionality, and evidence challenging the utility of this subscore as shown in Yarbrough et al..$^{15}$ This consequently resulted in a 12-point mCCOS tool (Table 2).

\section{Statistical Analysis}

Linear and ordinal regression statistical analyses were performed to identify if the included clinical variables of interest were predictors of $\mathrm{mCCOS}$ as a whole, or its individual components made up of pain and non-pain symptoms and complications. Statistical significance was set a priori at $\mathrm{p}<0.05$. Furthermore, the CSI was assessed separately from other clinical variables to exclude asymptomatic patients, as the outcome measure is only applicable to symptomatic patients. Age at the time of surgery, duraplasty, and arachnoid dissection were controlled in the statistical models for effects they may have on CSI and other outcomes.

\section{Results}

\section{Patient Demographics}

Of the 65 patients who met the inclusion criteria, $60 \%$ of the patient cohort was female, and the average age at the time of surgery was 9.8 years (Table 3 ). The majority of patients were white/Caucasian $(\mathrm{n}=56)$ followed by African American $(n=8)$ and Asian/Pacific Islander $(n=1)$. The average length of follow-up was $9 \pm 5$ months.

\section{mCCOS and CSI Grades}

The mean mCCOS score for all patients was $10.4 \pm 1.4$ (range 6-12; Table 3); 75\% of the cohort had an mCCOS score between 10 and 12 . No significant differences in the mean mCCOS scores were identified when investigating symptom types, including headache location, preoperative symptom category, syrinx size, duraplasty, arachnoid dissection, and CSI grade.

Preoperative images of 63 patients (58 T2-weighted and 5 T1-weighted) were utilized to determine syrinx sizes. Two patients' syrinx sizes were unable to be measured due to missing preoperative imaging or an inability to adequately visualize the thoracic and lumbar spine. Pre- and postoperative syrinx sizes were similar across the total patient cohort, with median sizes of 7.4 and $3.7 \mathrm{~mm}$, respectively.

CSI grades were assigned to 53 patients with increas-
TABLE 4. Data distribution by variables of interest

\begin{tabular}{|c|c|c|}
\hline Variable & $\mathrm{n}(\%)$ & Mean mCCOS score \pm SD \\
\hline \multicolumn{3}{|c|}{ Location of headache } \\
\hline Posterior & $25(38)$ & $10.00 \pm 1.71$ \\
\hline Other & $20(31)$ & $10.65 \pm 1.23$ \\
\hline None & $20(31)$ & $10.65 \pm 0.93$ \\
\hline \multicolumn{3}{|c|}{ Preop symptom category } \\
\hline Myelopathic & $20(31)$ & $10.10 \pm 1.55$ \\
\hline Other & $23(35)$ & $10.35 \pm 1.56$ \\
\hline None & $22(34)$ & $10.73 \pm 0.94$ \\
\hline \multicolumn{3}{|c|}{ Peripheral neuropathy } \\
\hline Present & $24(37)$ & $10.17 \pm 1.43$ \\
\hline Absent & $41(63)$ & $10.54 \pm 1.34$ \\
\hline \multicolumn{3}{|l|}{ Size of syrinx, mm } \\
\hline$<6$ & $33(52)$ & $10.48 \pm 1.44$ \\
\hline$\geq 6$ & $30(48)$ & $10.43 \pm 1.28$ \\
\hline \multicolumn{3}{|l|}{ Duraplasty } \\
\hline Performed & $57(88)$ & $10.40 \pm 1.41$ \\
\hline Not performed & $8(12)$ & $10.37 \pm 1.19$ \\
\hline \multicolumn{3}{|c|}{ Arachnoid dissection } \\
\hline Performed & $38(58)$ & $10.45 \pm 1.41$ \\
\hline Not performed & $27(42)$ & $10.33 \pm 1.36$ \\
\hline \multicolumn{3}{|l|}{ CSI grade } \\
\hline 1 & $24(45)$ & $10.46 \pm 1.53$ \\
\hline 2 & $12(23)$ & $10.25 \pm 1.71$ \\
\hline 3 & $17(32)$ & $10.41 \pm 1.12$ \\
\hline
\end{tabular}

ingly severity from grades 1 to 3 . The distribution of grades was as follows: grade 1,45\%; grade 2,23\%; and grade $3,32 \%$. There were no significant differences in CSI grades among all patients $(\mathrm{p}=0.86)$.

\section{Preoperative Symptoms and CSI Grade Versus mCCOS Score}

Preoperative symptoms included posterior headache (n $=25)$, other headache $(\mathrm{n}=20)$, myelopathic neuropathy $(n=20)$, and peripheral neuropathy $(n=24)$. Syrinx measurements were evaluated preoperatively as $<6 \mathrm{~mm}(\mathrm{n}=$ $33)$ or $\geq 6 \mathrm{~mm}(\mathrm{n}=30)$. Duraplasty was performed on 57 patients, whereas arachnoid dissection was performed on 38 patients. A complete list of these symptoms and the correlating mean mCCOS scores is found in Table 4.

CSI was evaluated as a predictor of mCCOS scores and also did not demonstrate any significant correlations. Similarly, when evaluating the individual predictors in Table 5 , no variable demonstrated significance in determining a higher or lower mCCOS score. For example, compared to posterior headaches, patients with "other" headaches or no headache had a positive correlation with improved mCCOS scores. However, this relationship did not achieve statistical significance $(\mathrm{p}=0.16)$.

Subsequently, the mCCOS was broken down into three subcomponents: pain, non-pain, and complications. Each mCCOS score was then evaluated against preclinical 
TABLE 5. Predictors of mCCOS score

\begin{tabular}{|c|c|c|c|c|}
\hline \multirow[b]{2}{*}{ Variable } & \multirow[b]{2}{*}{ Coefficient } & \multicolumn{2}{|c|}{$\mathrm{Cl}$ of Coefficient } & \multirow[b]{2}{*}{$p$ Value } \\
\hline & & Lower Limit & Upper Limit & \\
\hline \multicolumn{5}{|l|}{ Model 1} \\
\hline Location of headache & & & & 0.16 \\
\hline Posterior & - & - & - & \\
\hline Other & 0.85 & -0.02 & 1.71 & \\
\hline None & 0.55 & -0.35 & 1.45 & \\
\hline Preop symptom category & & & & 0.66 \\
\hline Myelopathic & - & - & - & \\
\hline Other & -0.05 & -0.93 & 0.83 & \\
\hline None & 0.33 & -0.56 & 1.23 & \\
\hline Size of syrinx, mm & & & & 0.40 \\
\hline$\geq 6$ & 0.32 & -0.41 & 1.04 & \\
\hline$<6$ & - & - & - & \\
\hline Duraplasty & & & & 0.69 \\
\hline Performed & - & - & - & \\
\hline Not performed & -0.25 & -1.47 & 0.98 & \\
\hline Arachnoid dissection & & & & 0.59 \\
\hline Performed & - & - & - & \\
\hline Not performed & -0.22 & -1.37 & 0.93 & \\
\hline \multicolumn{5}{|l|}{ Model 2} \\
\hline CSI grade* & & & & 0.95 \\
\hline 1 & - & - & - & \\
\hline 2 & -0.16 & -1.12 & 0.81 & \\
\hline 3 & -0.11 & -0.64 & 0.42 & \\
\hline
\end{tabular}

predictors and CSI grades to determine the relationship. Those patients who presented with no headache had a statistically significant decrease in their pain (neck pain, shoulder pain, or dysesthesia in the upper extremities) as measured by mCCOS score (pain component; $\chi^{2}[2, \mathrm{n}=$ $20]=6.43, p=0.04)$. All other preclinical predictors, including CSI grades, were nonsignificant in demonstrating correlations to mCCOS subcomponents (Table 6).

\section{Discussion}

Preoperative surgical prediction models are useful in a few ways. First, models can predict those patients who are at risk for a surgical complication. For example, predictors of mortality have been studied in patients with Chiari type II malformation and myelomeningocele. ${ }^{16}$ For patients with CM-I, longer operative time and length of stay of at least 5 days were associated with perioperative adverse events. ${ }^{17}$ Hence, understanding preoperative risk can be critical in preventing postoperative complications. However, a validated tool serving this purpose has not been established in the pediatric population for CM-I decompression. Second, preoperative surgical models can be used to screen pediatric patients with risk factors for postoperative intensive care unit admission or mortality. ${ }^{18,19}$ Finally, preoperative models can be used to select patients in whom the surgical intervention is most optimal. Hence, this study aimed to identify whether the CSI could be used as a preoperative tool to predict postoperative outcomes via the mCCOS score.

The CSI has been shown to be a powerful tool to identify patients with key neuroimaging and clinical findings to predict patient-reported satisfaction. ${ }^{13}$ Those with classic CM-I headaches improved, while myelopathic pain represented a patient population likely unresponsive to surgery. ${ }^{13}$ Although other centers have confirmed the external validity of the CSI, ${ }^{20}$ this tool is not a treatment protocol. ${ }^{13}$ As a preoperative administrative tool used to stratify patients, the CSI still has limitations, including scoring patients with concurrent headaches and signs of myelopathy, variations in timing of surgery, and unreliable history at early ages (i.e., determining presence/lack of headache in a 6-month-old). ${ }^{21}$

From an outcome perspective, the most comprehensive literature review was performed by Greenberg et al. ${ }^{13} \mathrm{Mul}-$ tiple outcome tools were identified and critically appraised for CM-I validity and reliability. Examples of these tools include the Karnofsky Performance Scale, Noudel et al.'s adapted functional grading system, ${ }^{24}$ the Japanese Orthopaedic Association scale, the Limonadi score, and the CCOS. ${ }^{13}$ Of the 17 tools identified and appraised, only the CCOS was validated in children. However, the tool was 
TABLE 6. Predictors by mCCOS components

\begin{tabular}{|c|c|c|c|}
\hline \multirow[b]{2}{*}{ Variable } & \multicolumn{3}{|c|}{ CCs by CCOS Components } \\
\hline & Pain & Non-Pain & Complications \\
\hline \multicolumn{4}{|l|}{ Model 1} \\
\hline \multicolumn{4}{|c|}{ Location of headache } \\
\hline Posterior & - & - & - \\
\hline Other & $3.15^{*}$ & 0.89 & 0.46 \\
\hline None & 0.66 & -0.07 & 0.02 \\
\hline \multicolumn{4}{|c|}{ Preop symptom category } \\
\hline Myelopathic & - & - & - \\
\hline Other & -0.75 & 0.38 & 0.98 \\
\hline None & 1.85 & -0.16 & 1.91 \\
\hline \multicolumn{4}{|c|}{ Peripheral neuropathy } \\
\hline Present & - & - & - \\
\hline Absent & 0.21 & -0.90 & 0.07 \\
\hline \multicolumn{4}{|l|}{ Size of syrinx, $\mathrm{mm}$} \\
\hline$\geq 6$ & 0.78 & 0.51 & -1.19 \\
\hline$<6$ & - & - & - \\
\hline \multicolumn{4}{|l|}{ Duraplasty } \\
\hline Performed & - & - & - \\
\hline Not performed & -0.77 & -0.36 & 0.20 \\
\hline \multicolumn{4}{|c|}{ Arachnoid dissection } \\
\hline Performed & - & - & - \\
\hline Not performed & 0.48 & -0.40 & -0.92 \\
\hline \multicolumn{4}{|l|}{ Model 2} \\
\hline \multicolumn{4}{|l|}{ CSI grade $\dagger$} \\
\hline 1 & - & - & - \\
\hline 2 & 0.07 & -0.12 & -1.49 \\
\hline 3 & 0.60 & -0.58 & -0.30 \\
\hline
\end{tabular}

designed for retrospective chart review to comment on pain, non-pain, functionality, and complication. This tool was not validated as a prospective measure of operative success for CM-I decompression. ${ }^{13}$ Additionally, the external validity of the functionality subscore of the CCOS was inadequate. ${ }^{22}$ Among other limitations, the CCOS tends to cluster at high scores because few patients have poor outcomes. ${ }^{22}$

Our attempt was to determine whether the CSI could be used a predictor for postoperative outcome using the $\mathrm{mCCOS}$ as the postoperative measure. Preclinical variables, performance of duraplasty/arachnoid dissection, and CSI grades were not correlated to changes in the mCCOS. Additionally, apart from lack of headache and improved mCCOS pain component, no statistically significant trends were established on multivariate regression. Despite its presurgical administrative value, the initial grade on the CSI does not determine patient outcome when evaluated by the mCCOS. While lack of headache was statistically significant in correlating a more optimal pain score on the mCCOS, those without pain initially were unlikely to develop pain postoperatively.
There are five notable limitations of this study. First, this is a single-institution study, and therefore our findings need to be corroborated by a multicenter effort. Second, this is a retrospective study, and is thus at risk of recall bias. To reduce recall bias, the study period was limited to a specific and recent timeframe. Third, this study is subject to selection biases. Patients who are symptomatic are likely to follow up more closely, while healthier patients may forgo neurosurgical appointments once their pain resolves. To limit this bias, multiple efforts were made to contact the patient and ensure quality follow-up. Fourth, the functional component of the CCOS was removed due to unreliability in capturing these data retrospectively, and therefore a modified CCOS was evaluated. Fifth, the CCOS poorly differentiates between asymptomatic and symptomatic patients. For example, an asymptomatic patient with a successful surgical decompression may have an "unchanged" score. As aforementioned, the external validity of this variable is questionable, but may still impact changes in the overall CCOS score.

\section{Conclusions}

The CSI was not found to be a reliable marker of surgical outcome as measured by the mCCOS. Furthermore, the lack of variation in mCCOS scores across our patient cohort also may suggest the mCCOS to be an inadequate measure of surgical outcomes. Although the results of this study are negative, there is a clear demonstration of limitations in our current tools for predicting CM-I outcomes. There continues to be a gap in our knowledge and understanding of how to reliably predict postoperative outcomes in patients with CM-I undergoing decompression.

\section{References}

1. Tubbs RS, Lyerly MJ, Loukas M, et al. The pediatric Chiari I malformation: a review. Childs Nerv Syst. 2007;23(11):12391250.

2. Baisden J. Controversies in Chiari I malformations. Surg Neurol Int. 2012;3(suppl 3):S232-S237.

3. Tubbs RS, Beckman J, Naftel RP, et al. Institutional experience with 500 cases of surgically treated pediatric Chiari malformation Type I. J Neurosurg Pediatr. 2011;7(3):248256.

4. Aitken LA, Lindan CE, Sidney S, et al. Chiari type I malformation in a pediatric population. Pediatr Neurol. 2009;40(6):449-454.

5. Attenello FJ, McGirt MJ, Gathinji M, et al. Outcome of Chiari-associated syringomyelia after hindbrain decompression in children: analysis of 49 consecutive cases. Neurosurgery. 2008;62(6):1307-1313.

6. Caldarelli M, Novegno F, Vassimi L, et al. The role of limited posterior fossa craniectomy in the surgical treatment of Chiari malformation Type I: experience with a pediatric series. $J$ Neurosurg. 2007;106(3)(suppl):187-195.

7. James HE, Brant A. Treatment of the Chiari malformation with bone decompression without durotomy in children and young adults. Childs Nerv Syst. 2002;18(5):202-206.

8. Kennedy BC, Kelly KM, Phan MQ, et al. Outcomes after suboccipital decompression without dural opening in children with Chiari malformation Type I. J Neurosurg Pediatr. 2015;16(2):150-158.

9. Navarro R, Olavarria G, Seshadri R, et al. Surgical results of posterior fossa decompression for patients with Chiari I malformation. Childs Nerv Syst. 2004;20(5):349-356. 
10. Parker SR, Harris P, Cummings TJ, et al. Complications following decompression of Chiari malformation Type I in children: dural graft or sealant? J Neurosurg Pediatr. 2011;8(2):177-183.

11. Yilmaz A, Kanat A, Musluman AM, et al. When is duraplasty required in the surgical treatment of Chiari malformation type I based on tonsillar descending grading scale? World Neurosurg. 2011;75(2):307-313.

12. Aliaga L, Hekman KE, Yassari R, et al. A novel scoring system for assessing Chiari malformation type I treatment outcomes. Neurosurgery. 2012;70(3):656-665.

13. Greenberg JK, Yarbrough CK, Radmanesh A, et al. The Chiari Severity Index: a preoperative grading system for Chiari malformation type 1. Neurosurgery. 2015;76(3):279-285.

14. Hekman KE, Aliaga L, Straus D, et al. Positive and negative predictors for good outcome after decompressive surgery for Chiari malformation type 1 as scored on the Chicago Chiari Outcome Scale. Neurol Res. 2012;34(7):694-700.

15. Yarbrough CK, Greenberg JK, Smyth MD, et al. External validation of the Chicago Chiari Outcome Scale. J Neurosurg Pediatr. 2014;13(6):679-684.

16. McDowell MM, Blatt JE, Deibert CP, et al. Predictors of mortality in children with myelomeningocele and symptomatic Chiari type II malformation. J Neurosurg Pediatr. 2018;21(6):587-596.

17. Vedantam A, Mayer RR, Staggers KA, et al. Thirty-day outcomes for posterior fossa decompression in children with Chiari type 1 malformation from the US NSQIP-Pediatric database. Childs Nerv Syst. 2016;32(11):2165-2171.

18. Anand KJ, Hopkins SE, Wright JA, et al. Statistical models to predict the need for postoperative intensive care and hospitalization in pediatric surgical patients. Intensive Care Med. 2001;27(5):873-883.

19. Lian C, Xie Z, Wang Z, et al. Pediatric preoperative risk factors to predict postoperative ICU admission and death from a multicenter retrospective study. Paediatr Anaesth. 2016;26(6):637-643.

20. Pisapia JM, Merkow MB, Brewington D, et al. External validity of the Chiari Severity Index and outcomes among pediatric Chiari I patients treated with intra- or extra-dural decompression. Childs Nerv Syst. 2017;33(2):313-320.
21. Tayebi Meybodi K. Chiari Severity Index: a novel grading system intended for preoperative counseling. Neurosurgery. 2015;77(5):E841-E842.

22. Yarbrough CK, Greenberg JK, Park TS. Clinical outcome measures in Chiari I malformation. Neurosurg Clin N Am. 2015;26(4):533-541.

23. Hadley DM. The Chiari malformations. J Neurol Neurosurg Psychiatry. 2002;72(suppl 2):ii38-ii40.

24. Noudel R, Gomis P, Sotoares G, et al. Posterior fossa volume increase after surgery for Chiari malformation Type I: a quantitative assessment using magnetic resonance imaging and correlations with the treatment response. Clinical article. J Neurosurg. 2011;115:647-658.

\section{Disclosures}

The authors report no conflict of interest concerning the materials or methods used in this study or the findings specified in this paper.

\section{Author Contributions}

Conception and design: Brooks, Lim. Acquisition of data: Brooks, Lim, Guidry. Analysis and interpretation of data: Lim, Guidry. Drafting the article: Ahluwalia, Foster. Critically revising the article: Ahluwalia, Foster. Reviewed submitted version of manuscript: Foster. Statistical analysis: Zhao. Administrative/technical/material support: Ahluwalia, Gannon. Study supervision: Ahluwalia, Wellons, Shannon.

\section{Correspondence}

Ranbir Ahluwalia: Florida State University College of Medicine, Tallahassee,FL.ra16@med.fsu.edu. 